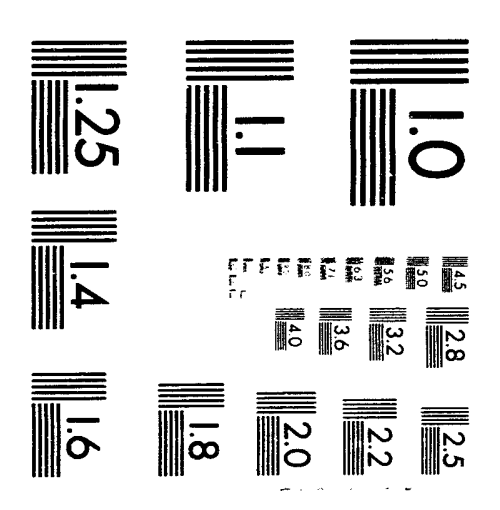



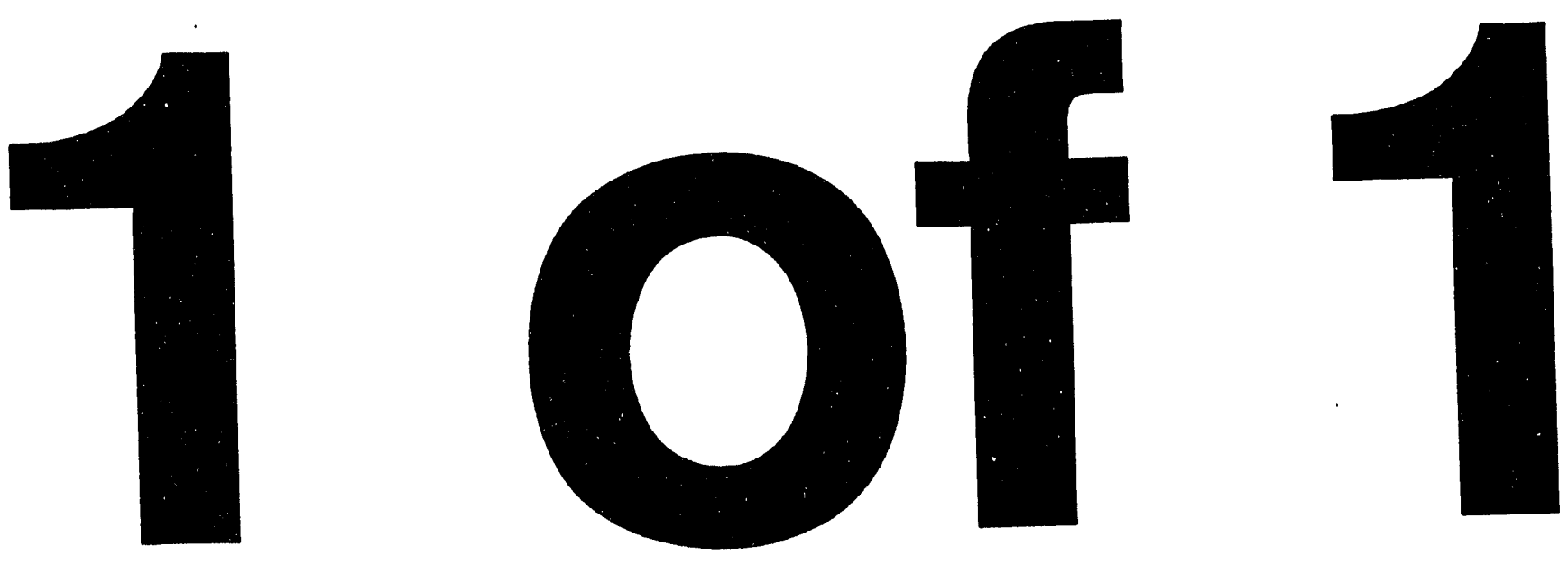


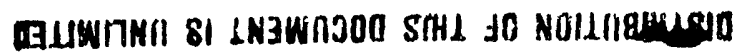

(1)

\section{$43184 \mathrm{~W}$}

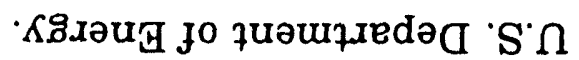

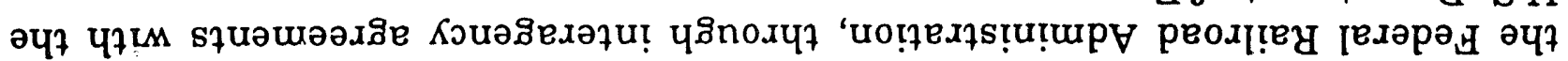
pue sxəəu!̣ి

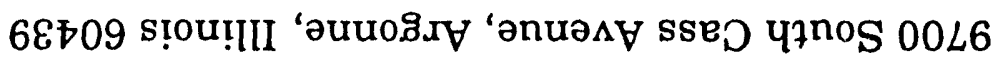

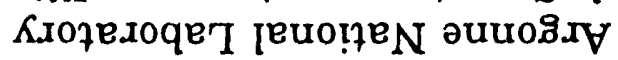

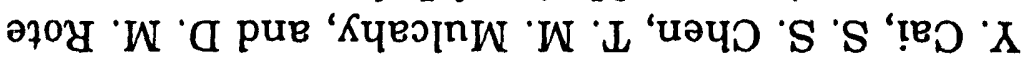

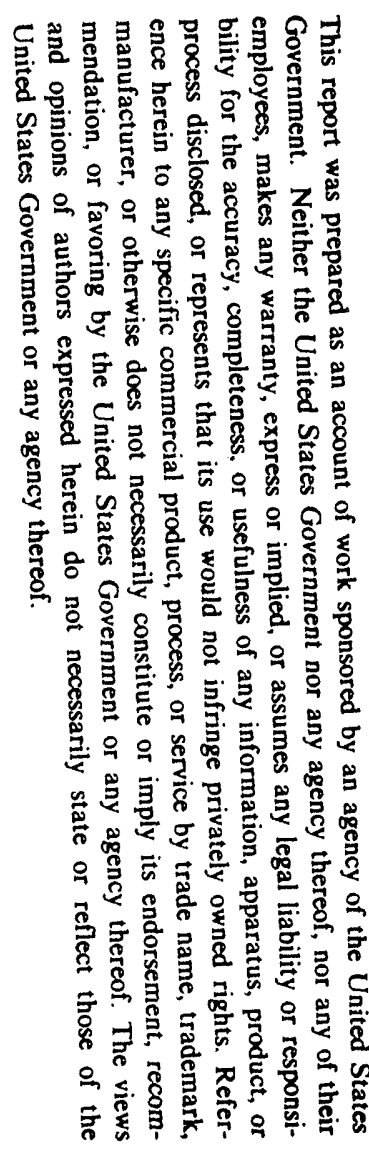

Kq

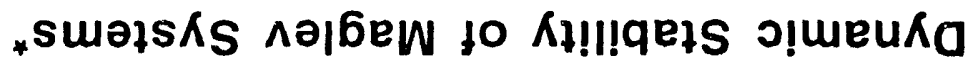




\title{
DYNAMIC STABILITY OF MAGLEV SYSTEMS
}

\author{
Y. Cai, S. S. Chen, T. M. Mulcahy, and D. M. Rote \\ Argonne National Laboratory \\ Argonne, IL 60439
}

\begin{abstract}
Because dynamic instabilities are not acceptable in any commercial maglev system, it is important to consider dynamic instability in the development of all maglev systems. This study considers the stability of maglev systems based on experimental data, scoping calculations, and simple mathematical models. Divergence and flutter are obtained for coupled vibration of a three-degree-of-freedom maglev vehicle on a guideway consisting of double L-shaped aluminum segments. The theory and analysis developed in this study provides basic stability characteristics and identifies future research needs for maglev systems.
\end{abstract}

\section{INTRODUCTION}

The dynamic response of maglev systems is important in several respects: safety and ride quality, guideway design, and system cost. Ride quality is determined by the response of the vehicles, as well as environmental factors such as humidity and noise. The dynamic response of vehicles is the key element in the determination of ride quality, and vehicle stability is one of the important elements relative to safety. To design a proper guideway that provides acceptable 
ride quality in the stable region, the vehicle dynamics must be understood. Furthermore, we trade-off between guideway smoothness and the levitation and control systems must be considered if maglev systems are to be made economically feasible. The link between guideway and other maglev components is the vehicle dynamics. For a commercial maglev system, detailed vehicle dynamics must be analyzed and tested.

For safety reason, maglev systems should be stable. Magnetic forces are basically position-dependent, while some are also velocity-dependent. These motion-dependent magnetic forces can induce various types of instability. In addition, the periodic structure of the motion-dependent magnetic forces may also induce parametric resonance and combination resonance.

Some analytical and experimental studies have been performed to understand the stability characteristics of maglev systems. Several examples are summarized below:

\section{Theoretical Studies}

- Davis and Wilkie [1] studied a magnetic coil moving over a conducting track and concluded that negative damping occurs for velocities greater than the characteristic velocity based on thin-track theory.

- Ohno et al. [2] studied the pulsating lift forces in a linear synchronous motor. These pulsating forces may cause parametric resonance and combination resonance in addition to the heave and pitch oscillations.

- Baiko et al. (Chu and Moon [3]) considered the interactions of the induced eddy currents with on-board superconducting magnets and found possible heave instabilities. 


\section{Experimental Studies}

- An experimental vehicle floating above a large rotating wheel was found by Moon [4] to have sway-yaw instabilities.

- Experiments performed at MIT on a test track showed the pitch-heave instability (Moon [5]).

\section{Experimental/Analytical Studies}

- A conducting guideway, consisting of L-shaped aluminum segments attached to a rotating wheel to simulate the full-scale Japanese guideway at Miyazaki, was studied experimentally and analytically by Chu and Moon [3]. Divergence and flutter were obtained for coupled yaw-lateral vibration; the divergence leads to two stable equilibrium yaw positions, and the flutter instability leads to a limit cycle of coupled yaw and lateral motions in the neighborhood of the magnetic drag peak.

- Variation of the magnetic lift force due to the variation of the levitated height corresponding to the sinusoidal guideway roughness was studied by Yabuno et al. [6]. Parametric resonance of the heaving and pitching motions were found to be possible.

Based on the published analytical results and experimental data, it is obvious that different types of dynamic instabilities can occur in maglev systems. Because dynamic instabilities are not acceptable for any commercial maglev system, it is important to consider the dynamic instability in the development of all maglev systems. 
The objective of this study is to consider the stability of maglev systems based on experimental data, scoping calculations, and simple mathematical models. The objective is to provide some basic stability characteristics and to identify future research needs.

\section{MOTION-DEPENDENT MAGNETIC FORCES}

\section{Motion-Dependent Magnetic-Force Coefficients}

Magnetic forces are needed for any vehicle dynamics analysis, guideway structural design, design of fastenings, and prediction of ride quality. These force components are considered from the standpoint of vehicle stability.

As an example, consider a vehicle with six degrees of freedom, three translations, $u_{x}, u_{y}, u_{z}$ and three rotation, $\omega_{x}, \omega_{y}, \omega_{z}$, as shown in Fig. 1 . Let $U$ be the vector consisting of the six motion components; i.e.,

$$
U=\left\{\begin{array}{l}
u_{1} \\
u_{2} \\
u_{3} \\
u_{4} \\
u_{5} \\
u_{6}
\end{array}\right\}=\left\{\begin{array}{l}
u_{x} \\
u_{y} \\
u_{z} \\
\omega_{x} \\
\omega_{y} \\
\omega_{z}
\end{array}\right\}
$$

The velocity and acceleration are given by

$$
\dot{U}=\frac{\partial U}{\partial t}, \quad \text { and } \quad \ddot{U}=\frac{\partial^{2} U}{\partial t^{2}} \text {. }
$$

The motion-dependent magnetic forces can be written 


$$
f_{i}=\sum_{j=1}^{6}\left(m_{i j} \ddot{u}_{j}+c_{i j} \dot{u}_{j}+k_{i j} u_{j}\right)
$$

where $m_{i j}$, $c_{i j}$, and $k_{i j}$ are magnetic mass, damping, and stiffness coefficients. These coefficients can be obtained analytically, numerically, or experimentally, and are functions of the system parameters [7].

\section{Experimental Methods to Measure Motion-Dependent Magnetic-Force}

\section{Coefficients}

Quasistatic Motion Theory. The magnetic forces acting on an oscillating vehicle are equal, at any instant in time, to those of the same vehicle moving with a constant velocity with specific clearances equal to the actual instantaneous values. The magnetic forces depend on the deviation from a reference state of speed and clearance; i.e., the motion-dependent magnetic forces depend only on $u_{j}$, but not $\dot{u}_{j}$ and $\ddot{u}_{j}$, so that

$$
f_{i}=\sum_{j=1}^{6} k_{i j} u_{j}
$$

In this case, the magnetic forces are determined uniquely by the vehicle position. All elements of magnetic stiffness $k_{i j}$ can be obtained. To determine $k_{i j}$, the magnetic force component $f_{i}$ is measured as a function of $u_{j}$. The stiffness, $k_{i j}$, is given by

$$
\mathrm{k}_{\mathrm{ij}}=\frac{\partial \mathrm{f}_{\mathrm{i}}}{\partial \mathrm{u}_{\mathrm{j}}}
$$

In general, $\mathrm{k}_{\mathrm{ij}}$ is a function of $\mathrm{U}$. 
Unsteady Motion Theory. The magnetic forces acting on an oscillating vehicle will depend on $U, \dot{U}$, and $\ddot{U}$. The magnetic force based on the unsteady motion theory can be obtained by measuring the magnetic force acting on the vehicle oscillating in the magnetic field. For example, if the displacement component $u_{j}$ is excited, its displacement is given by

$$
u_{j}=\bar{u}_{j} \exp (\sqrt{-1} \omega t)
$$

The motion-dependent magnetic force of the component $f_{i}$ acting on the vehicle is given by

$$
f_{i}=\left[a_{i j} \cos \left(\psi_{i j}\right)+\sqrt{-1} a_{i j} \sin \left(\psi_{i j}\right)\right] \bar{u}_{j} \exp (\sqrt{-1} \omega t),
$$

where $a_{\mathrm{ij}}$ is the magnetic force amplitude and $\psi_{\mathrm{ij}}$ is the phase angle between the magnetic force and the vehicle displacement $u_{j}$. These values are measured experimentally.

Using Eqs. (3) and (6), we can also write the motion-dependent magnetic force component as

$$
f_{i}=\left(-m_{i j} \omega^{2}+\sqrt{-1} \omega c_{i j}+k_{i j}\right) \bar{u}_{j} \exp (\sqrt{-1} \omega t)
$$

Comparing Eqs. (7) and (8) yields

$$
c_{i j}=a_{i j} \sin \left(\psi_{i j}\right) / \omega, \quad m_{i j}=\left[k_{i j}-a_{i j} \cos \left(\psi_{i j}\right)\right] / \omega^{2} .
$$

Based on Eqs. (5) and (9), all motion-dependent magnetic-force matrices can be determined from two experiments: quasistatic motion and unsteady motion. 
If $m_{i j}$ and $c_{i j}$ are of no concern, the experiment using quasisteady motion is sufficient to determine $k_{i j}$.

\section{Quasistatic Motion-Dependent Magnetic-Force Coefficients of Maglev System with}

\section{L-Shaped Guideway}

An experiment, recently conducted at Argonne National Laboratory, investigated the lift, drag, and guidance magnetic forces on an $\mathrm{NdFeB}$ permanent magnet moving over an aluminum (6061-T6) L-shaped ring mounted on the top surface of a 1.2-m-diameter rotating wheel (shown schematically in Fig. 2). For a given rotating speed of the wheel, the lift and guidance magnetic forces were measured as the guidance gap $\mathrm{Y}^{*}$ and lift height $\mathrm{h}$ were varied. Figures 3a-3d show those measured forces as a function of $h$, with $\mathrm{Y}^{*}$ fixed $(12.7 \mathrm{~mm})$, or as a function of $Y^{*}$ with $h$ fixed $(h=7 \mathrm{~mm})$, when the surface velocity of the lateral leg of the guideway is $36.1 \mathrm{~m} / \mathrm{s}$, the highest velocity tested.

During testing, the long side of the $25.4 \times 50.4 \times 6.35$-mm rectangular magnet was oriented parallel to the direction of motion of the L-shaped guideway and was held stationary by a two-component force transducer comprising two BLH C2G1 load cells connected in series to measure the lift and guidance forces simultaneously. Laboratory weights were used to calibrate the transducer and assess crosstalk, which was found to be less than $2 \%$. The base of the load cell assembly was mounted on motorized stages that provided accurate positioning $( \pm 0.05 \mathrm{~mm})$. The out-of-roundness of the L-shaped guideway ring varied, but was always less than $\pm 0.15 \mathrm{~mm}$ for the lateral leg and $\pm 0.35 \mathrm{~mm}$ for the vertical leg. Ability to exactly position the magnet with respect to the guideway dominated our experimental error, estimated at $\pm 5 \%$.

Based on the magnetic force data shown in Fig. 3 we can calculate the quasistatic motion-dependent magnetic-force coefficients with Eq. (5). All 
elements of magnetic stiffness $\mathrm{k}_{\ell \ell}, \mathrm{k}_{\ell g}, \mathrm{k}_{\mathrm{g} \ell}$, and $\mathrm{k}_{\mathrm{gg}}$, were calculated and are shown in Fig. 4 with various $Y^{*}$ and $h$.

The curve fit to both magnetic forces and stiffnesses were derived using polynomial expressions (results are given in Figs. 3 and 4) and input into a computer code to simulate coupled vibrations of maglev vehicle.

\section{STABILITY OF MAGLEV SYSTEMS}

Without motion-dependent magnetic forces, the equation of motion for the vehicle can be written

$$
\left[\mathrm{M}_{\mathrm{v}}\right]\{\ddot{U}\}+\left[\mathrm{C}_{\mathrm{v}}\right]\{\dot{U}\}+\left[\mathrm{K}_{\mathrm{v}}\right]\{\mathrm{U}\}=\{\mathrm{Q}\}
$$

where $M_{V}$ is the vehicle mass matrix, $C_{V}$ is vehicle damping matrix, $K_{V}$ is vehicle stiffness matrix, and $Q$ is generalized excitation force.

The motion-dependent magnetic forces are given in Eq. (3). With motiondependent magnetic forces, Eq. (10) becomes

$$
\left[\mathrm{M}_{\mathrm{v}}+\mathrm{M}_{\mathrm{m}}\right]\{\ddot{\mathrm{U}}\}+\left[\mathrm{C}_{\mathrm{v}}+\mathrm{C}_{\mathrm{m}}\right]\{\dot{\mathrm{U}}\}+\left[\mathrm{K}_{\mathrm{v}}+\mathrm{K}_{\mathrm{m}}\right]\{\mathrm{U}\}=\{\mathrm{Q}\}
$$

where $M_{m}$ is the magnetic mass matrix, $C_{m}$ is magnetic damping matrix, and $K_{m}$ is magnetic stiffness; their elements are $m_{i j}, c_{i j}$, and $k_{i j}$.

Once the magnetic-force coefficients are known, analysis of vehicle stability is straightforward. Equation (11) may be written as

$$
[\mathrm{M}]\{\ddot{\mathrm{U}}\}+[\mathrm{C}]\{\dot{\mathrm{U}}\}+[\mathrm{K}]\{\mathrm{U}\}=\{\mathrm{Q}\}
$$


In general, $M, C$, and $K$ are functions of $U, \dot{U}$, and $\ddot{U}$; therefore, a complete solution is difficult to obtain. In many practical situations, one can ignore all nonlinear terms, such that $\mathrm{M}, \mathrm{C}$, and $\mathrm{K}$ are independent of vehicle motion.

By premultiplying by $\{\dot{U}\}^{\mathrm{T}}$ and forming the symnetric and antisymmetric components of the matrices

$$
\begin{array}{ll}
{\left[\mathrm{M}_{1}\right]=\frac{1}{2}\left([\mathrm{M}]+[\mathrm{M}]^{\mathrm{T}}\right),} & {\left[\mathrm{M}_{2}\right]=\frac{1}{2}\left([\mathrm{M}]-[\mathrm{M}]^{\mathrm{T}}\right),} \\
{\left[\mathrm{C}_{1}\right]=\frac{1}{2}\left([\mathrm{C}]+[\mathrm{C}]^{\mathrm{T}}\right),} & {\left[\mathrm{C}_{2}\right]=\frac{1}{2}\left([\mathrm{C}]-[\mathrm{C}]^{\mathrm{T}}\right),} \\
{\left[\mathrm{K}_{1}\right]=\frac{1}{2}\left([\mathrm{~K}]+[\mathrm{K}]^{\mathrm{T}}\right),} & {\left[\mathrm{K}_{2}\right]=\frac{1}{2}\left([\mathrm{~K}]-[\mathrm{K}]^{\mathrm{T}}\right),}
\end{array}
$$

we can separate the terms, giving

$$
\begin{aligned}
&\{\dot{U}\}^{\mathrm{T}} {\left[\mathrm{M}_{1}\right]\{\ddot{\mathrm{U}}\}+\{\dot{U}\}^{\mathrm{T}}\left[\mathrm{C}_{2}\right]\{\dot{U}\}+\{\dot{U}\}^{\mathrm{T}}\left[\mathrm{K}_{1}\right]\{\mathrm{U}\} } \\
&=-\left(\{\dot{U}\}^{\mathrm{T}}\left[\mathrm{M}_{2}\right]\{\ddot{\mathrm{U}}\}+\{\dot{U}\}^{\mathrm{T}}\left[\mathrm{C}_{1}\right]\{\dot{U}\}+\{\dot{U}\}^{\mathrm{T}}\left[\mathrm{K}_{2}\right]\{\mathrm{U}\}\right) .
\end{aligned}
$$

Equation (14) equates rates of work. The terms on the right-hand side of the equation produce a net work resultant when integrated over a closed path through the space $\{U\}$, the magnitude depending on the path taken. The forces corresponding to the matrices $\mathrm{M}_{2}, \mathrm{C}_{1}$, and $\mathrm{K}_{2}$, appearing on the right-hand side, are thus by definition the nonconservative parts of the forces represented by $M, C$, and $\mathrm{K}$. The terms on the left-hand side similarly can be shown to give rise to a zero work-resultant over any closed path, and therefore together are the sum of the rates of work from the potential forces and the rate of change of kinetic energy. 
Different types of instability can be classified according to the dominant terms in Eq. (14).

- Magnetic Damping Controlled Instability (single mode flutter): The dominant terms are associated with the symmetric damping matrix $\left[\mathrm{C}_{1}\right]$. Flutter arises because the magnetic damping forces create "negative damping," that is, a magnetic force that acts in phase with vehicle velocity.

- Magnetic Stiffness Controlled Instability (coupled mode flutter): The dominant terms are associated with the antisymmetric stiffness matrix $\left[\mathrm{K}_{2}\right]$. It is called coupled mode flutter because at least two modes are required to produce it.

Corresponding to the single-mode flutter and coupled-mode flutter, there may exist parametric resonance and combination resonance if the motion-dependent magnetic forces are a periodic function of time.

- Parametric Resonance: When the period of a motion-dependent magnetic force is a multiple of one of the natural frequencies of the vehicle, the vehicle may be dynamically unstable.

- Combination Resonance: When the period of the motion-dependent magnetic forces is equal to the sum or difference divided by an integer of the natural frequencies of the vehicle, the vehicle may also be subjected to dynamic instability.

In practical cases, two or more mechanisms may interact with one another, and Eq. (12) is applicable for general cases.

It is noted that maglev systems are subjected to several groups of forces, including magnetic forces, aerodynamic forces, and guideway perturbation. The theory presented in this paper is applicable to maglev systems when they are 
subjected to other types of forces. In particular, the aerodynamic effects can be described exactly the same way as those given in Eqs. (1)-(14) and the dynamic response characteristics to aerodynamic forces are similar to magnetic forces (see Ref. 8 for details).

\section{SIMPLIFIED VEHICLE MODELS FOR DYNAMIC INSTABILITY}

Different vehicles are considered, in order to gain an understanding of stability characteristics. We have calculated two-, three-, and six-degree-offreedom vehicles to investigate dynamic instability for maglev systems [7]. However, only the three-degree-of-freedom vehicle with the double L-shaped sheet guideway is described in this paper.

Figure 5 shows the cross section of a vehicle and guideway. Assume that the vehicle is traveling at a constant velocity along $x$ direction. Two permanent magnets are attached to the bottom of vehicle and provide lift and guidance force $F_{L_{1}}, F_{L_{2}}, F_{G_{1}}$ and $F_{G_{2}}$ (see Fig. 5). Assuming at the initial state that $h_{1}=h_{2}=h_{0}$ and $g_{1}=g_{2}=g_{0}$, we can express the geometries of vehicle and guideway as

$$
\begin{array}{ll}
\mathrm{L}_{1}=\mathrm{L}_{2}=\mathrm{S}=76.2(\mathrm{~mm}), & \mathrm{W}=152.4+\mathrm{S}-2 \mathrm{~g}_{0}(\mathrm{~mm}), \quad \mathrm{H}=0.9 \mathrm{~W}(\mathrm{~mm}) \\
\mathrm{a}=0.5 \mathrm{H}(\mathrm{mm}), & \mathrm{b}=0.5(\mathrm{~W}-25.4)(\mathrm{mm})
\end{array}
$$

Equations of motion for this three-degree-of-freedom maglev system can be written as

$$
\begin{aligned}
& m \ddot{z}+C \dot{z}=F_{L_{1}}+F_{L_{2}}-m g \\
& I \ddot{\theta}+E \dot{\theta}=\left(F_{G_{1}}+F_{G_{2}}\right) a+\left(F_{G_{1}}+F_{G_{2}}\right) b \\
& m \ddot{y}+D \dot{y}=F_{G_{1}}+F_{G_{2}}
\end{aligned}
$$


where $m$ is the mass of the vehicle, $C$ and $D$ are damping ratios; $I$ is the moment of inertia about the center of mass inertia moment of the vehicle [I = $\left.(\mathrm{m} / 12)\left(\mathrm{H}^{2}+\mathrm{W}^{2}\right)\right]$. $\mathrm{F}_{\mathrm{L}_{1}}, \mathrm{~F}_{\mathrm{L}_{2}}, \mathrm{~F}_{\mathrm{G}_{1}}$, and $\mathrm{F}_{\mathrm{G}_{2}}$ are lift and guidance forces and are functions of $y$ and $z$. At equilibrium position, they are $F_{L_{10}}\left(y_{0}, z_{0}\right), F_{L_{20}}\left(y_{0}, z_{0}\right)$, $\mathrm{F}_{\mathrm{G}_{10}}\left(\mathrm{y}_{0}, \mathrm{z}_{0}\right)$, and $\mathrm{F}_{\mathrm{G}_{20}}\left(\mathrm{y}_{0}, \mathrm{z}_{0}\right)$. Applying them to Eqs. (15),

$$
\mathrm{F}_{\mathrm{L}_{10}}=\mathrm{F}_{\mathrm{L}_{20},}, \quad \mathrm{~F}_{\mathrm{L}_{10}}+\mathrm{F}_{\mathrm{L}_{20}}=\mathrm{mg}, \quad \mathrm{F}_{\mathrm{G}_{10}}=-\mathrm{F}_{\mathrm{G}_{20}}
$$

therefore,

$$
\mathrm{m}=\frac{\mathrm{F}_{\mathrm{L}_{10}}+\mathrm{F}_{\mathrm{L}_{20}}}{\mathrm{~g}}=\frac{2 \mathrm{~F}_{\mathrm{L}}\left(\mathrm{h}_{0}\right)}{\mathrm{g}}
$$

Let

$$
\mathrm{z}=\frac{1}{2}\left(\mathrm{u}_{1}+\mathrm{u}_{2}\right), \quad \mathrm{y}=\mathrm{u}_{3}, \quad \theta=\left(\mathrm{u}_{1}-\mathrm{u}_{2}\right) / 2 \mathrm{~b}
$$

where $u_{1}, u_{2}$, and $u_{3}$ are shown in Fig. 6. Equations (15) can be rewritten as

$$
\begin{aligned}
& \mathrm{m}\left(\ddot{\mathrm{u}}_{1}+\ddot{\mathrm{u}}_{2}\right)+\mathrm{c}\left(\dot{\mathrm{u}}_{1}-\dot{\mathrm{u}}_{2}\right)=2\left(\mathrm{~F}_{\mathrm{L}_{1}}+\mathrm{F}_{\mathrm{L}_{2}}-\mathrm{mg}\right) \\
& \frac{\mathrm{I}}{\mathrm{b}}\left(\ddot{\mathrm{u}}_{1}-\ddot{\mathrm{u}}_{2}\right)+\frac{\mathrm{E}}{\mathrm{b}}\left(\dot{\mathrm{u}}_{1}-\dot{\mathrm{u}}_{2}\right)=2 \mathrm{a}\left(\mathrm{F}_{\mathrm{G}_{1}}+\mathrm{F}_{\mathrm{G}_{2}}\right)+2 \mathrm{~b}\left(\mathrm{~F}_{\mathrm{G}_{1}}-\mathrm{F}_{\mathrm{G}_{2}}\right) \\
& \mathrm{m} \ddot{\mathrm{u}}_{3}+\mathrm{D} \dot{\mathrm{u}}_{3}=\mathrm{F}_{\mathrm{G}_{1}}+\mathrm{F}_{\mathrm{G}_{2}} .
\end{aligned}
$$

Note the reduced dependence of the forces on the new displacements of Eq. (18):

$$
\mathrm{F}_{\mathrm{L}_{1}}=\mathrm{F}_{\mathrm{L}_{1}}\left(\mathrm{u}_{1}, \mathrm{u}_{3}\right), \quad \mathrm{F}_{\mathrm{L}_{2}}=\mathrm{F}_{\mathrm{L}_{2}}\left(\mathrm{u}_{2}, \mathrm{u}_{3}\right), \quad \mathrm{F}_{\mathrm{G}_{1}}=\mathrm{F}_{\mathrm{G}_{1}}\left(\mathrm{u}_{1}, \mathrm{u}_{3}\right), \quad \mathrm{F}_{\mathrm{G}_{2}}=\mathrm{F}_{\mathrm{G}_{2}}\left(\mathrm{u}_{2}, \mathrm{u}_{3}\right)
$$

Let 


$$
u_{i}=u_{i 0}+v_{i} \quad i=1,2 .
$$

The linear approximation of lift and guidance forces can be expressed as

$$
\begin{aligned}
& \mathrm{F}_{\mathrm{L}_{1}}=\mathrm{F}_{\mathrm{L}_{10}}+\frac{\partial \mathrm{F}_{\mathrm{L}_{1}}}{\partial \mathrm{v}_{1}} \mathrm{v}_{1}+\frac{\partial \mathrm{F}_{\mathrm{L}_{1}}}{\partial \mathrm{v}_{3}} \mathrm{v}_{3} \\
& \mathrm{~F}_{\mathrm{L}_{2}}=\mathrm{F}_{\mathrm{L}_{20}}+\frac{\partial \mathrm{F}_{\mathrm{L}_{2}}}{\partial \mathrm{v}_{2}} \mathrm{v}_{2}+\frac{\partial \mathrm{F}_{\mathrm{L} 2}}{\partial \mathrm{v}_{3}} \mathrm{v}_{3} \\
& \mathrm{~F}_{\mathrm{G}_{1}}=\mathrm{F}_{\mathrm{G}_{10}}+\frac{\partial \mathrm{F}_{\mathrm{G}_{1}}}{\partial \mathrm{v}_{1}} \mathrm{v}_{1}+\frac{\partial \mathrm{F}_{\mathrm{G} 1}}{\partial \mathrm{v}_{3}} \mathrm{v}_{3} \\
& \mathrm{~F}_{\mathrm{G}_{2}}=\mathrm{F}_{\mathrm{G}_{20}}+\frac{\partial \mathrm{F}_{\mathrm{G}_{2}}}{\partial \mathrm{v}_{2}} \mathrm{v}_{2}+\frac{\partial \mathrm{F}_{\mathrm{G} 2}}{\partial \mathrm{v}_{3}} \mathrm{v}_{3}
\end{aligned}
$$

Using Eqs. (16) and (22), we can rewrite Eq. (19) as

$$
\begin{aligned}
& \ddot{v}_{1}+\ddot{v}_{2}+\frac{C}{m} \dot{v}_{1}+\frac{C}{m} \dot{v}_{2}-\frac{2}{m} \frac{\partial \mathrm{F}_{L_{1}}}{\partial v_{1}} \mathrm{v}_{1}-\frac{2}{\mathrm{~m}} \frac{\partial \mathrm{F}_{\mathrm{L}_{2}}}{\partial \mathrm{v}_{2}} \mathrm{v}_{2}-\frac{1}{\mathrm{~m}}\left(\frac{\partial \mathrm{F}_{\mathrm{G}_{1}}}{\partial \mathrm{v}_{3}}+\frac{\partial \mathrm{F}_{\mathrm{G}_{2}}}{\partial \mathrm{v}_{3}}\right) \mathrm{v}_{3}=0 \\
&-\ddot{\mathrm{v}}_{1}+\ddot{\mathrm{v}}_{2}-\frac{\mathrm{E}}{\mathrm{I}} \dot{\mathrm{v}}_{1}+\frac{\mathrm{E}}{\mathrm{I}} \dot{\mathrm{v}}_{2}+\left(\frac{2 \mathrm{cb}}{\mathrm{I}} \frac{\partial \mathrm{F}_{\mathrm{L}_{1}}}{\partial \mathrm{v}_{1}}+\frac{2 \mathrm{~b}^{2}}{\mathrm{I}} \frac{\partial \mathrm{F}_{\mathrm{G}_{1}}}{\partial \mathrm{v}_{1}}\right) \mathrm{v}_{1} \\
&+\left(\frac{2 \mathrm{ab}}{\mathrm{I}} \frac{\partial \mathrm{F}_{\mathrm{L}_{2}}}{\partial \mathrm{v}_{2}}+\frac{2 \mathrm{~b}^{2}}{\mathrm{I}} \frac{\partial \mathrm{F}_{\mathrm{G}_{2}}}{\partial \mathrm{v}_{2}}\right) \mathrm{v}_{2} \\
&+\left[\frac{2 \mathrm{ab}}{\mathrm{I}}\left(\frac{\partial \mathrm{F}_{\mathrm{L}_{1}}}{\partial \mathrm{v}_{3}}+\frac{\partial \mathrm{F}_{\mathrm{L}_{2}}}{\partial \mathrm{v}_{3}}\right)+\frac{2 \mathrm{~b}^{2}}{\mathrm{I}}\left(\frac{\partial \mathrm{F}_{\mathrm{G}_{1}}}{\partial \mathrm{v}_{3}}+\frac{\partial \mathrm{F}_{\mathrm{G}_{2}}}{\partial \mathrm{v}_{3}}\right)\right] \mathrm{v}_{3}=0 \\
& \ddot{\mathrm{v}}_{3}+\frac{\mathrm{D}}{\mathrm{m}} \dot{\mathrm{v}}_{3}-\frac{1}{\mathrm{~m}} \frac{\partial \mathrm{F}_{\mathrm{L}_{1}}}{\partial \mathrm{v}_{1}} \mathrm{v}_{1}-\frac{1}{\mathrm{~m}} \frac{\partial \mathrm{F}_{\mathrm{L}_{2}}}{\partial \mathrm{v}_{2}} \mathrm{v}_{2}-\frac{1}{\mathrm{~m}}\left(\frac{\partial \mathrm{F}_{\mathrm{L}_{1}}}{\partial \mathrm{v}_{3}}+\frac{\partial \mathrm{F}_{\mathrm{L}_{2}}}{\partial \mathrm{v}_{3}}\right) \mathrm{v}_{3}=0
\end{aligned}
$$

With magnetic forces and stiffnesses measured by the experiments (see Figs. 3 and 4), the eigenvalues and eigenvectors of a maglev vehicle on a double L- 
shaped guideway were calculated with the theoretical model developed in this section. Some very interesting results were obtained from those calculations.

Figure 7 shows that eigenvalues of vehicle motion versus levitation height vary when guidance gaps are fixed $\left(\mathrm{g}_{1}=\mathrm{g}_{2}=\mathrm{Y}^{*}=12.7 \mathrm{~mm}\right)$. The first mode $\omega_{1}$ shows an uncoupled heave motion; the imaginary part of its eigenvalue is zero. The second and third modes are coupled roll-sway motions. Within a range of height $\mathrm{h}$ of 19.0 to $35 \mathrm{~mm}$, the imaginary parts of eigenvalues appear not to be zero. This indicates that within this range flutter does exist for these coupled rollsway vibrations. Table 1 gives eigenvectors and modal shapes of these three modes of vehicle motion.

Figure 8 shows eigenvaiues of vehicle motion versus lateral location of vehicle when $\mathrm{g}_{1}=\mathrm{g}_{2}=\mathrm{g}_{0}=25 \mathrm{~mm}$, and levitation height $\mathrm{h}=7 \mathrm{~mm}$, respectively. We notice that for the third mode, which presents the transversal motion of vehicle, the real part is zero and the imaginary part is not zero within a certain region. This indicates that the divergence is subjected to the lateral motion of vehicle with those vehicle and guideway parameters. Figure 9 shows the real part of third mode versus lateral location of the vehicle when parameterequilibrium guidance gap varies as $\mathrm{g}_{1}=\mathrm{g}_{2}=\mathrm{g}_{0}=10 \mathrm{~m}, 15 \mathrm{~mm}, 20 \mathrm{~mm}$, and $25 \mathrm{~mm}$. We found that the divergence only appears with the case of $\mathrm{g}_{0}=25 \mathrm{~mm}$.

Note that the measured and calculated data for motion-dependent magneticforces and force coefficients are very limited and the damping effects were not considered in the above analysis. Even though the divergence and flutter appear in the eigenvalue results, we still have difficulty in completely predicting dynamic instability of this three-degree-of-freedom maglev vehicle model. Further research steps are needed in modeling and understanding the dynamic instability of maglev systems. 


\section{CLOSING REMARKS}

- Motion-dependent magnetic forces are the key elements in modeling and understanding the dynamic instabilities of maglev systems. At this time, it appears that very limited data are available for motion-dependent magnetic forces.

- Various options can be used to stabilize a maglev system: passive electrodynamic primary suspension damping, active electrodynamic primary suspension damping, passive mechanical secondary suspension, and active mechanical secondary suspension. With a better understanding of vehicle stability characteristics, a better control law can be adopted to ensure a high level of ride comfort and safety.

- Computer programs are needed for screening new system concepts, evaluating various designs, and predicting of vehicle response. It appears that the stability characteristics of maglev vehicles under different conditions have not been studied in detail in existing computer codes. When information on motion-dependent magnetic forces becomes available, the existing computer codes can be significantly improved.

- Instabilities of maglev system models have been observed at Argonne National Laboratory and other organizations. An integrated experimental/analytical study of stability characteristics is an important part of any research activities concerning maglev systems.

\section{ACKNOWLEDGMENTS}

This work was performed under the sponsorship of the U.S. Army Corps of Engineers and the Federal Railroad Administration, through interagency agreements with the U.S. Department of Energy. 
Additional thanks to $\mathrm{S}$. Winkelman for performing tests on magnetic forces.

\section{REFERENCES}

1. L.C. Davis and D.F. Wilkie, "Analysis of Motion of Magnetic Levitation Systems: Implications," J. Appl. Phys., Vol. 42, No. 12, pp. 4779-4793, 1971.

2. E. Ohno, M. Iwamoto, and T. Yamada, "Characteristic of Superconductive Magnetic Suspension and Propulsion for High-Speed Trains," Proc. IEEE, Vol. 61, No. 5, pp. 579-586, 1973.

3. D. Chu and F.C. Moon, "Dynamic Instabilities in Magnetically Levitated Models," J. Appl. Phys., Vol. 54, No. 3, pp. 1619-1625, 1983.

4. F.C. Moon, "Laboratory Studies of Magnetic Levitation in the Thin Track Limit," IEEE Trans. on Magnetics, MAG-10, No. 3, pp. 439-442, Sept. 1974.

5. F.C. Moon, "Vibration Problems in Magnetic Levitation and Propulsion," Transport Without Wheels, ed. by E. R. Laithwaite, pp. 122-161, Elek Science, London, 1975.

6. H. Yabuno, Y. Takabayashi, M. Yoshizawa, and Y. Tsujioka, "Bounding and Pitching Oscillations of a Magnetically Levitated Vehicle Caused by Guideway Roughness," Int. Conference Maglev 89, pp. 405-410, 1989.

7. Y. Cai, S.S. Chen, T.M. Mulcahy, and D.M. Rote, "Dynamic Stability of Maglev Systems," Argonne National Laboratory Report ANL-92/21, April 1992.

8. S.S. Chen, Flow-Induced Vibration of Circular Cylindrical Tubes, Hemisphere Publishing Co., New York, 1987. 
Table 1. Eigenvectors of vehicle motion $\left(Y^{*}=12.7 \mathrm{~mm}\right)$

\begin{tabular}{|c|c|c|c|c|c|c|c|c|c|}
\hline & \multicolumn{3}{|c|}{$\mathrm{h}=15.0 \mathrm{~mm}$} & \multicolumn{3}{|c|}{$\mathrm{h}=25 \mathrm{~mm}$} & \multicolumn{3}{|c|}{$\mathrm{h}=37 \mathrm{~mm}$} \\
\hline & $v_{1}$ & $\mathrm{v}_{2}$ & v3 & $\mathrm{v}_{1}$ & $\mathrm{v}_{2}$ & $v_{3}$ & $v_{1}$ & $\mathbf{v}_{2}$ & $v_{3}$ \\
\hline $\begin{array}{l}\text { Uncoupled } \\
\text { heave mode }\end{array}$ & 1 & 1 & 0 & 1 & $\overline{1}$ & $\overline{0}$ & 1 & $\overline{1}$ & 0 \\
\hline$\omega_{1}$ Coupled roll- & 1 & -1 & -0.009 & 0.586 & -0.586 & -0.332 & -1 & 1 & -0.205 \\
\hline $\begin{array}{l}\text { sway mode } \omega_{2} \\
\text { Coupled roll- } \\
\text { sway mode } \omega_{3}\end{array}$ & -0.545 & 0.545 & 1 & -0.810 & 0.810 & 0.060 & 1 & -1 & 0.448 \\
\hline
\end{tabular}




\section{Figure Captions}

Fig. 1. Displacement components of a maglev system

Fig. 2. Schematic for magnetic force measurement on L-shaped aluminum sheet guideway

Fig. 3. Measured lift and guidance magnetic forces

Fig. 4. Measured lift and guidance magnetic stiffness

Fig. 5. Maglev system with a vehicle on a double L-shaped aluminum sheet guideway

Fig. 6. Displacement components of three-degree-of-freedom vehicle

Fig. 7. Eigenvalues of maglev system vs. vehicle levitation height with $\mathrm{Y}^{*}=$ $12.7 \mathrm{~mm}$

Fig. 8. Eigenvalues of maglev system vs. lateral location of vehicle with $h=7$ $\mathrm{mm}$ and $\mathrm{g}_{0}=25 \mathrm{~mm}$

Fig. 9. Real part of eigenvalues of maglev system vs. lateral location of vehicle with $\mathrm{h}=7 \mathrm{~mm}$ and $\mathrm{g}_{0}=10,15,20$, and $25 \mathrm{~mm}$ 

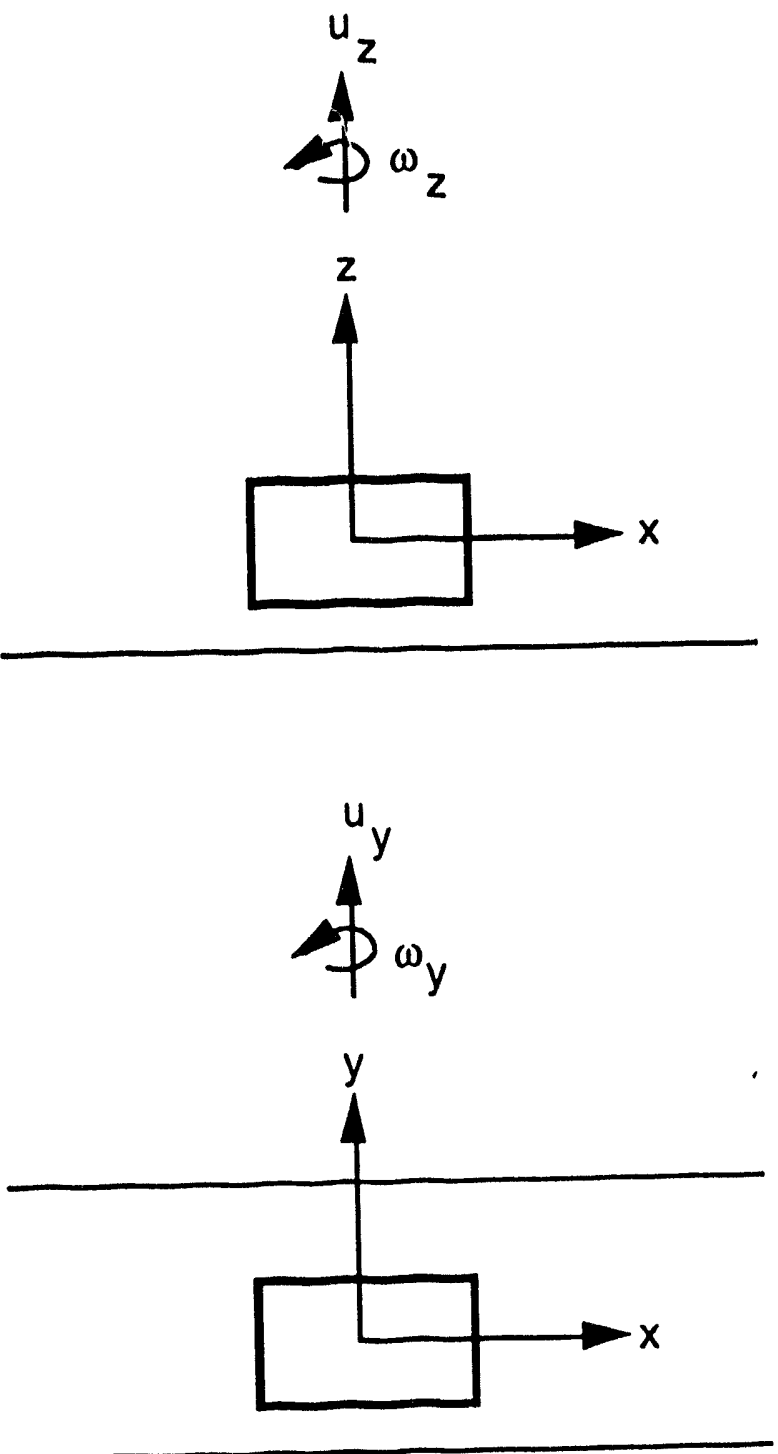

$t^{\omega} u_{x}$ 


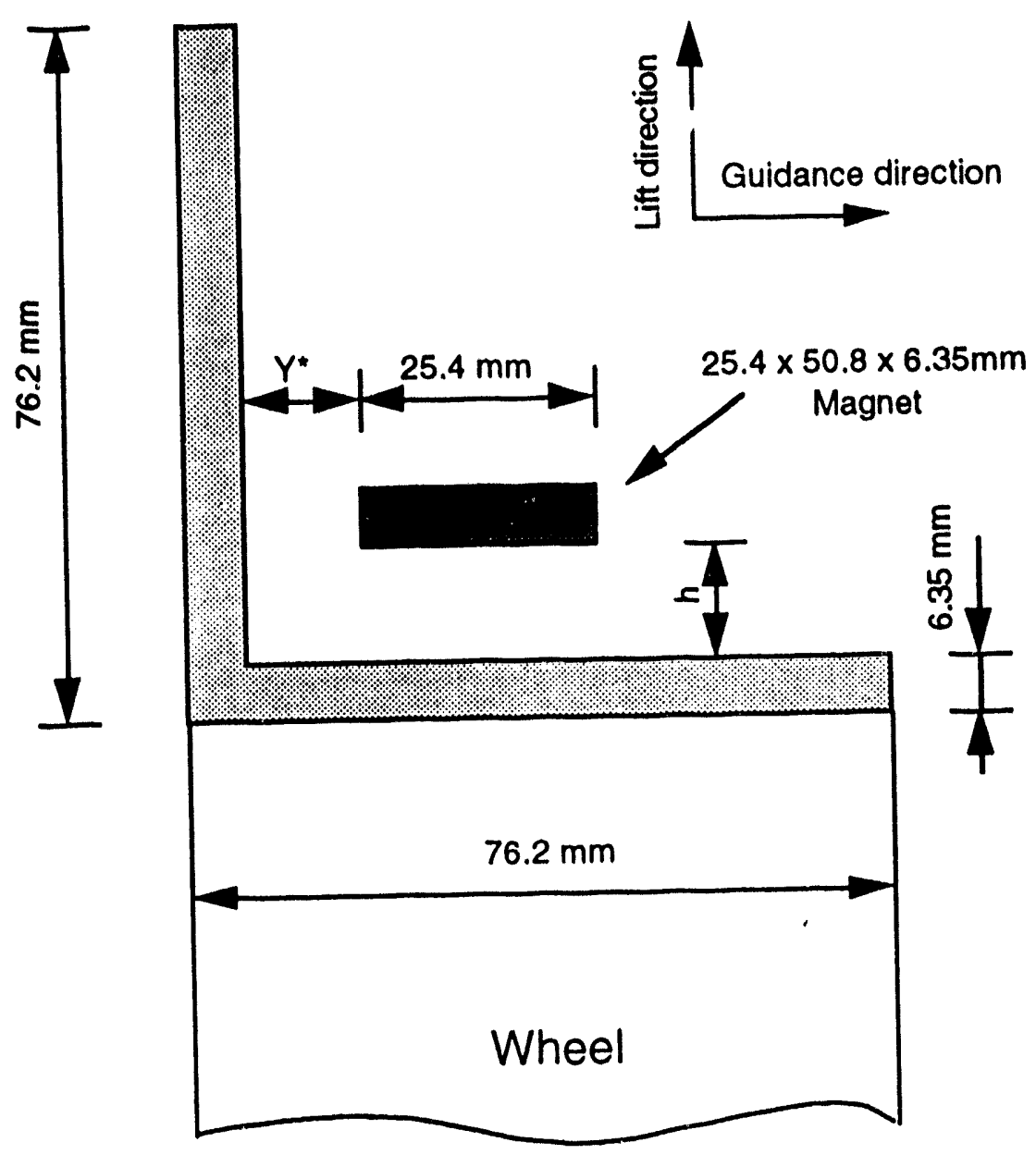




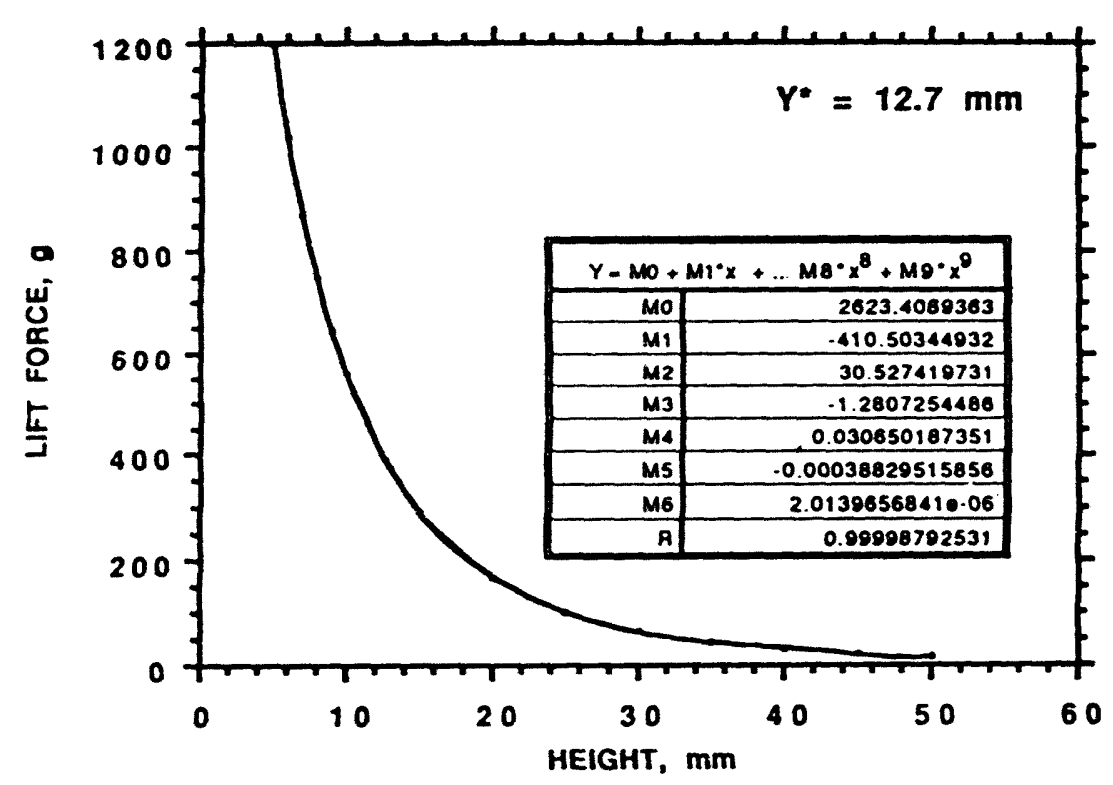

(a)

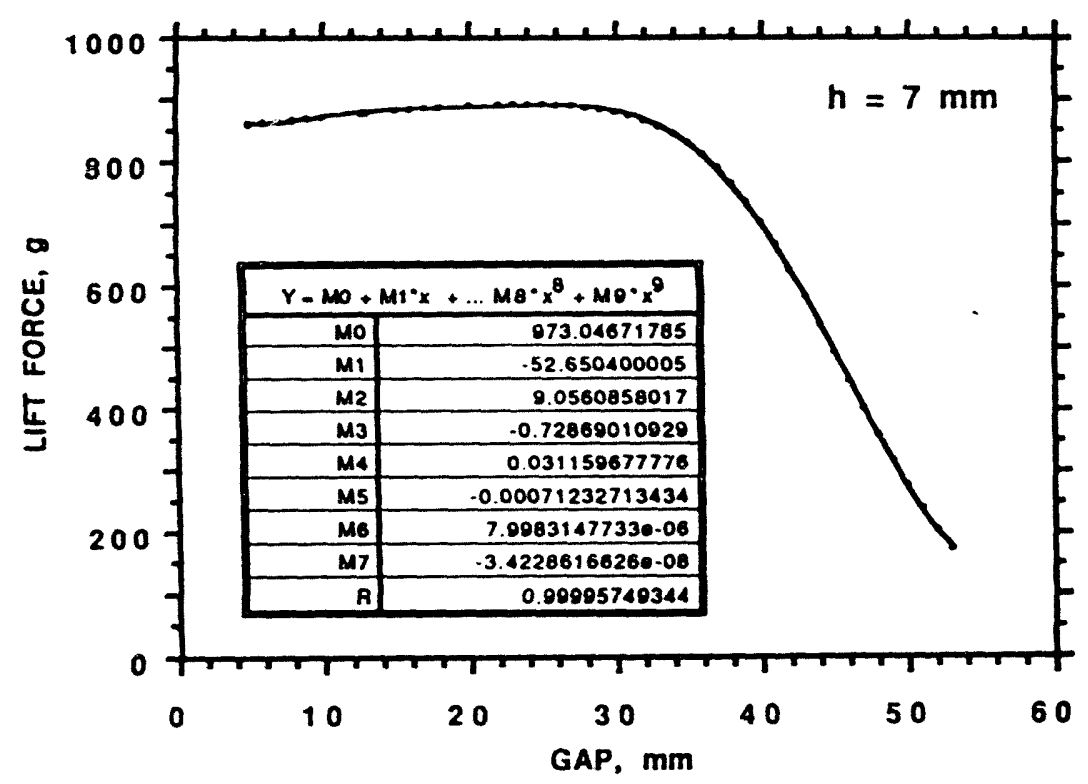

(b)

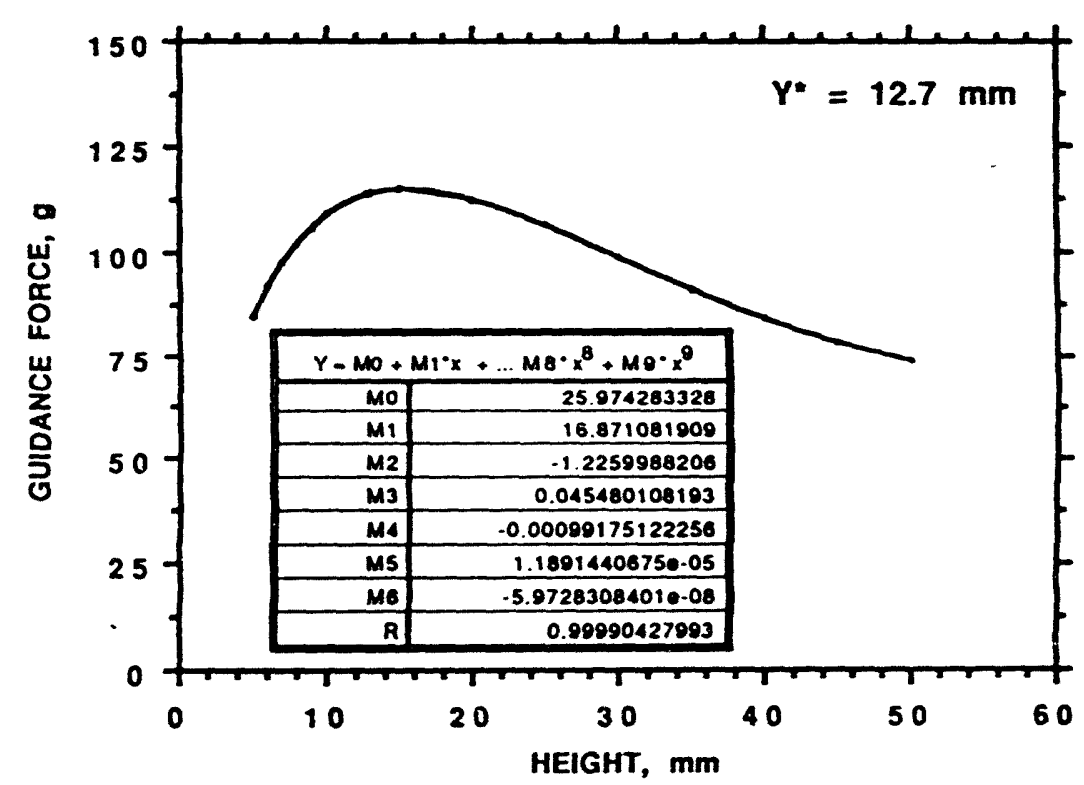

(c)

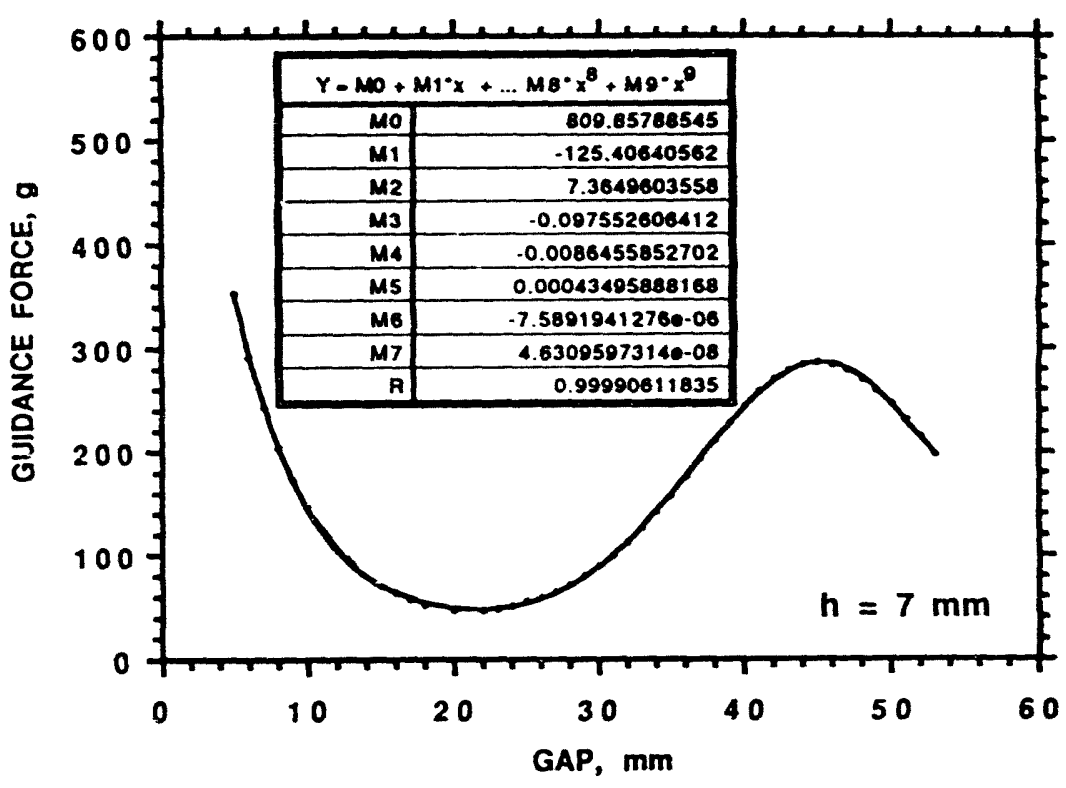

(d) 


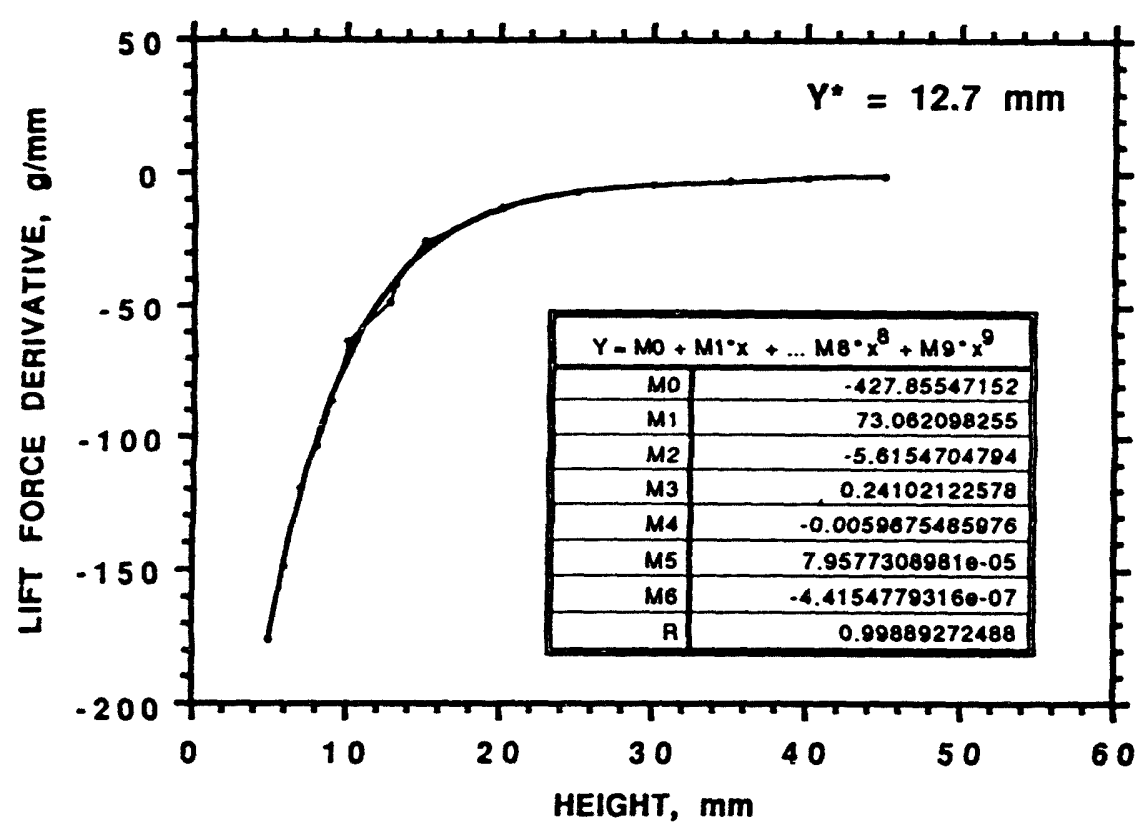

(a)

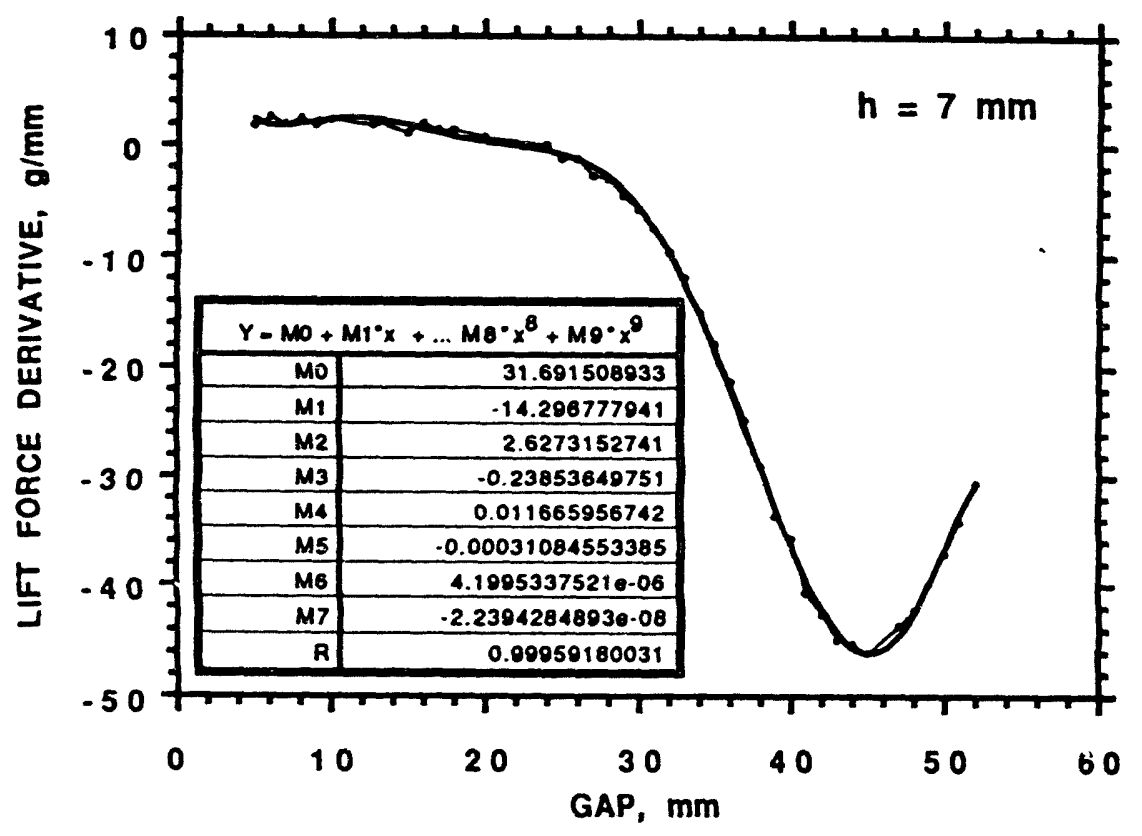

(b)

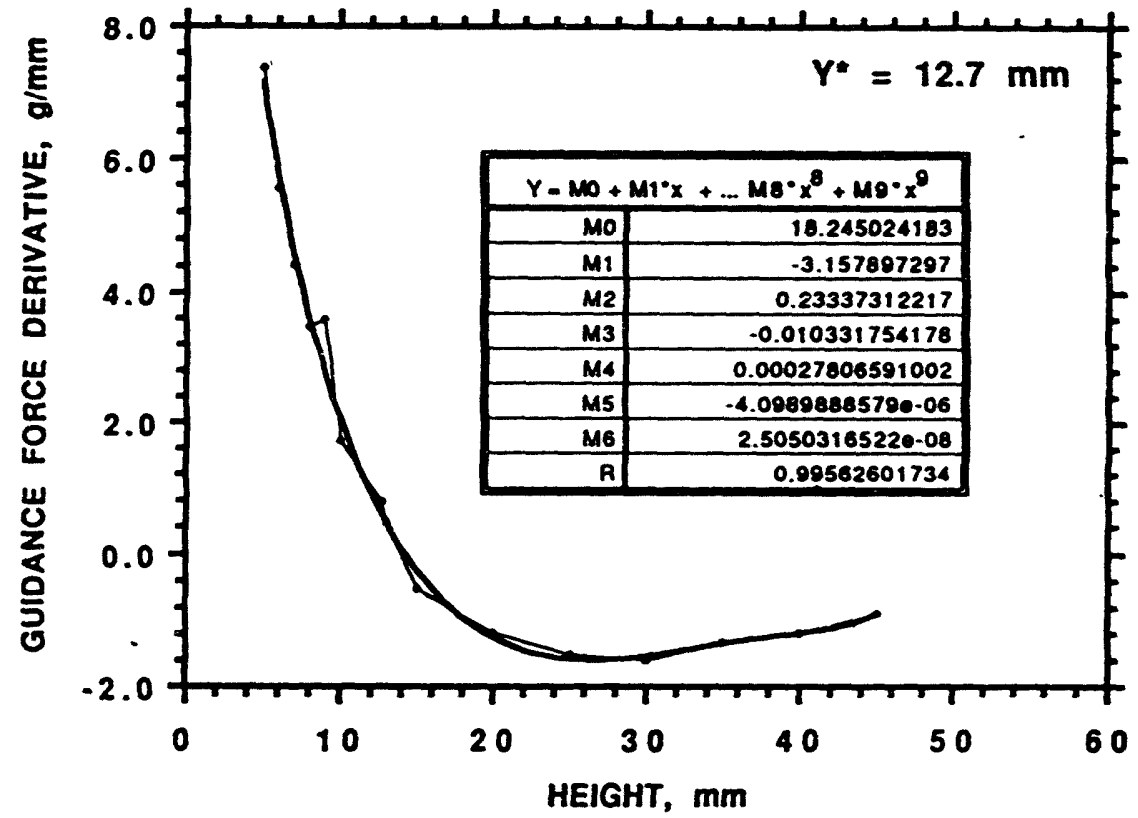

(c)

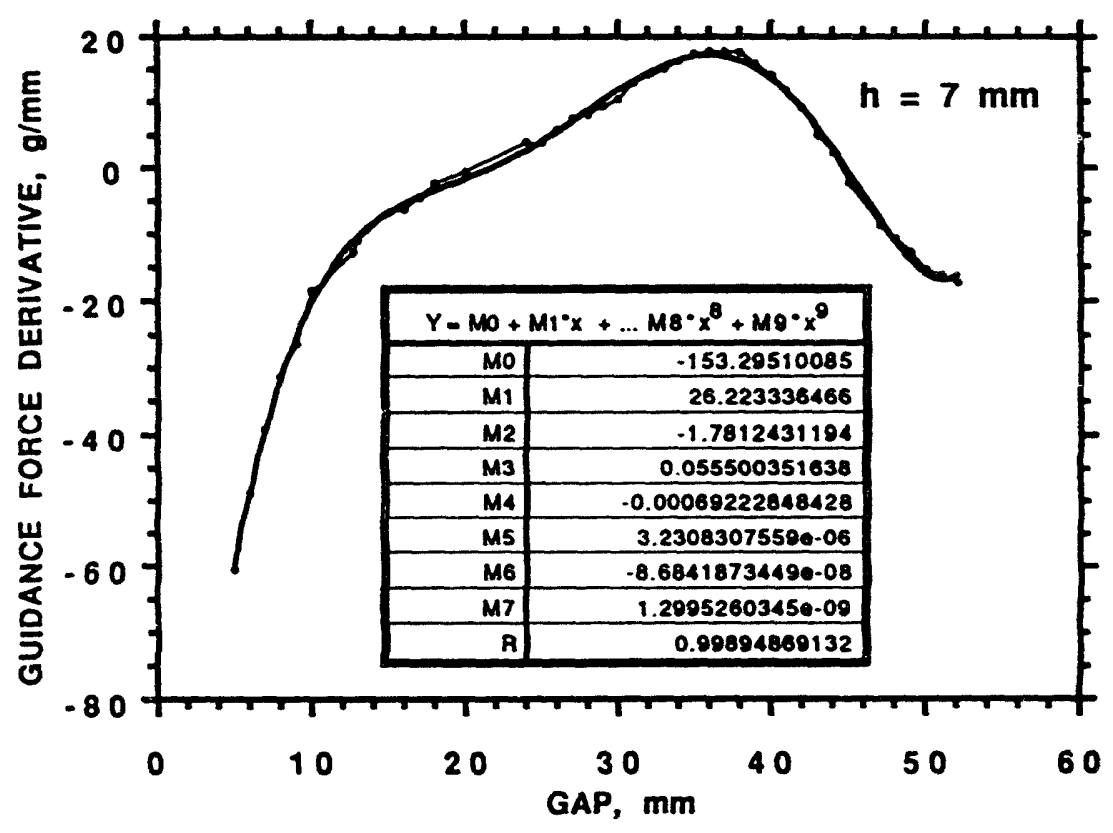

(d) 

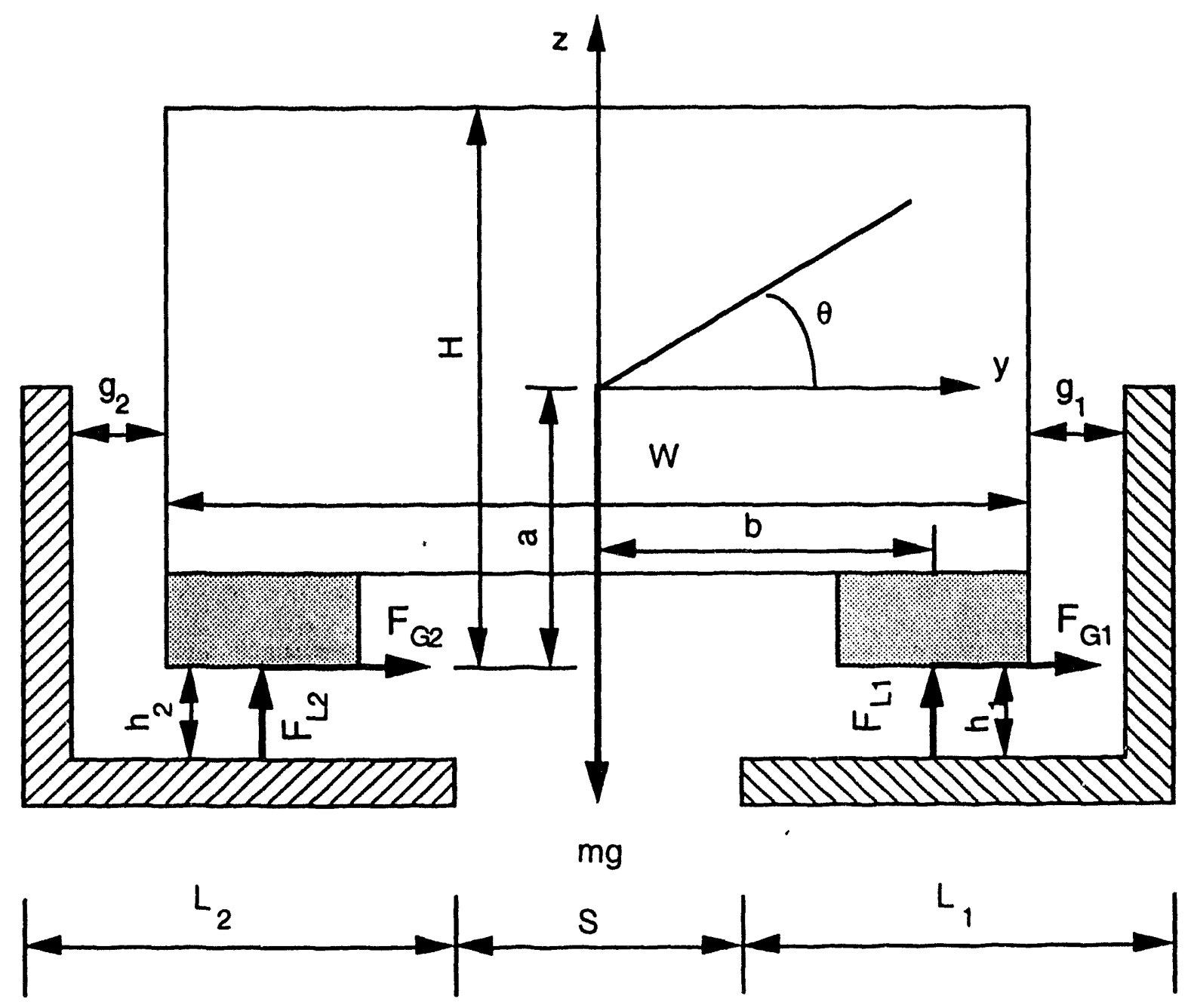

F. 8.5 


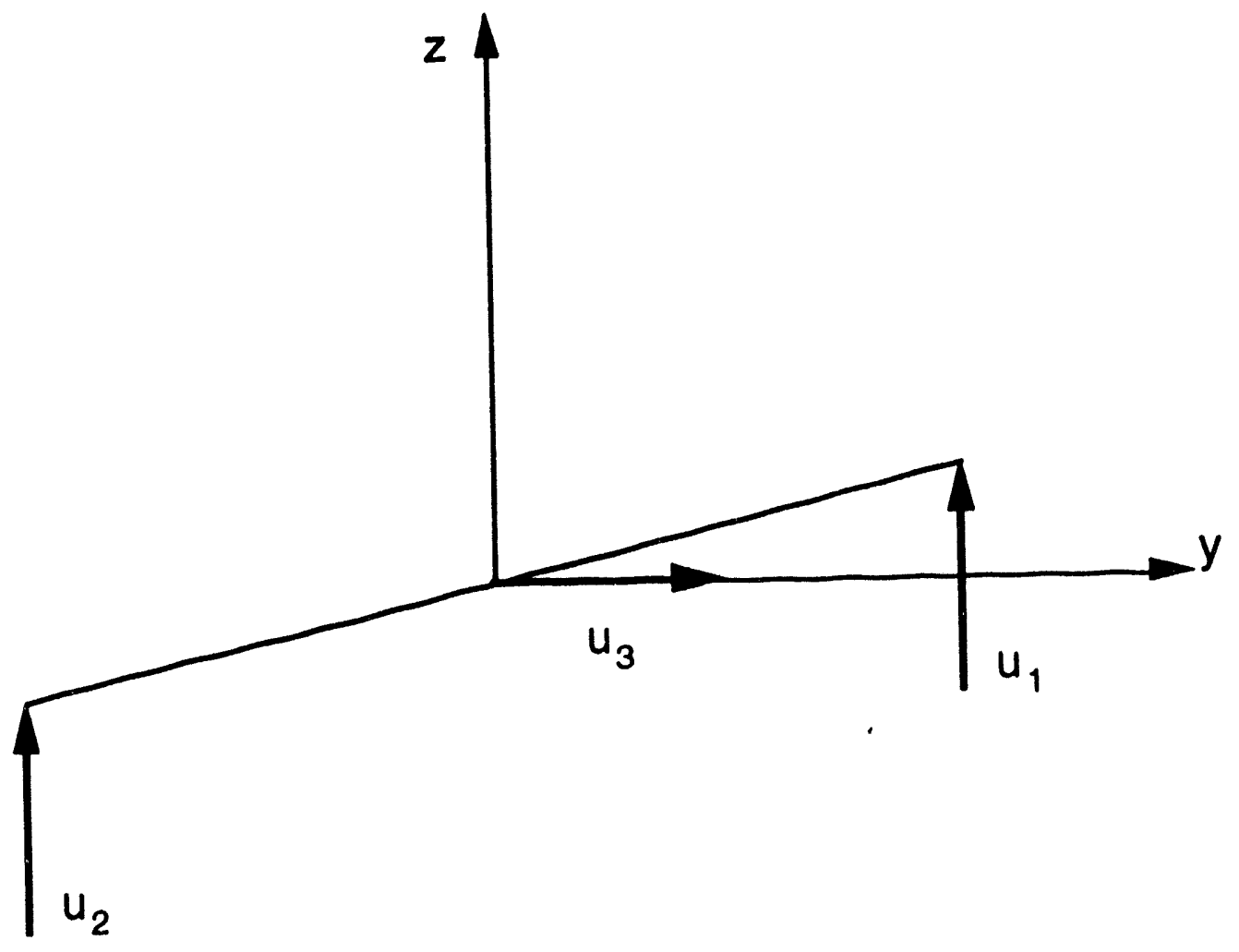

Fig. 6 


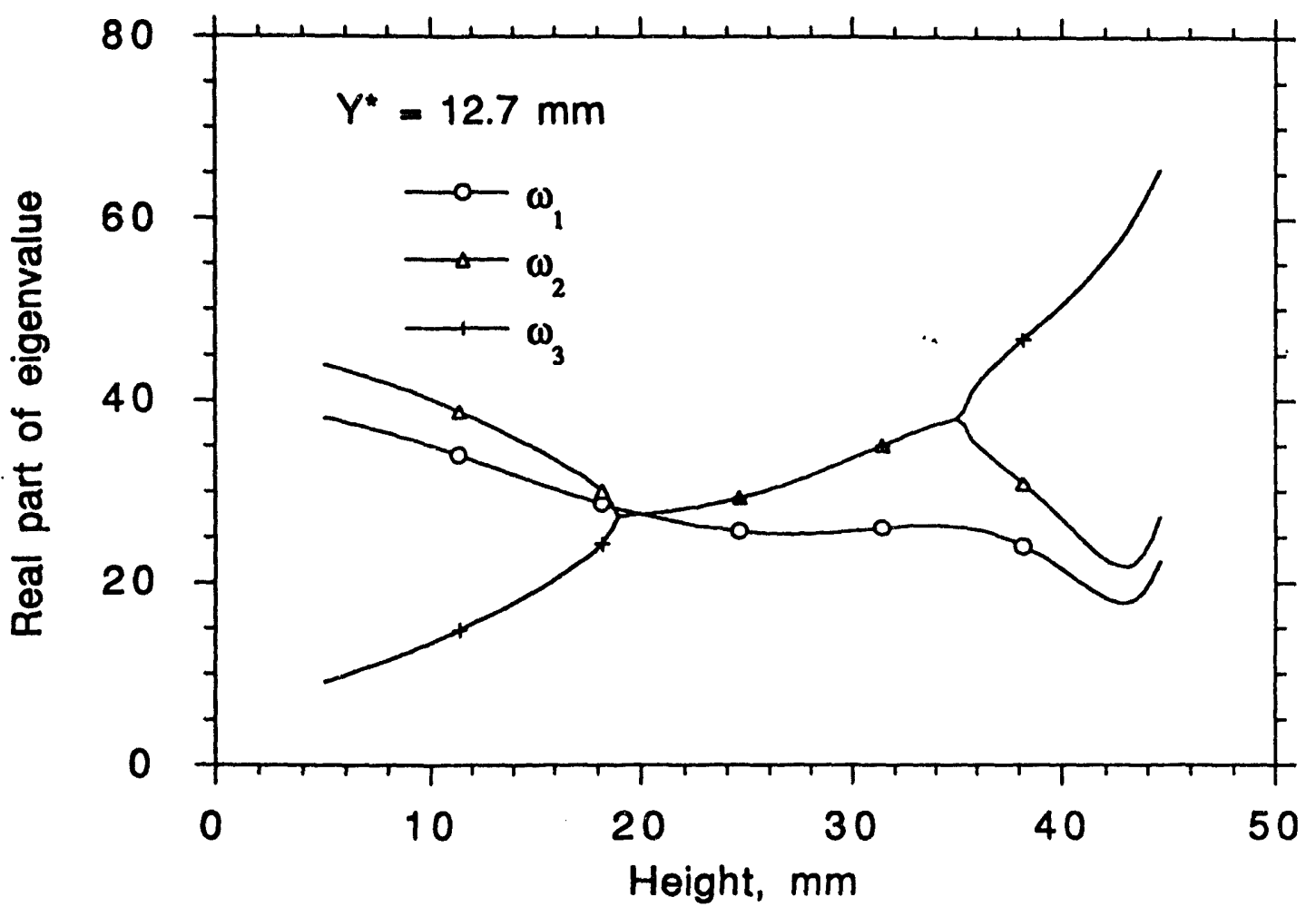

(a)

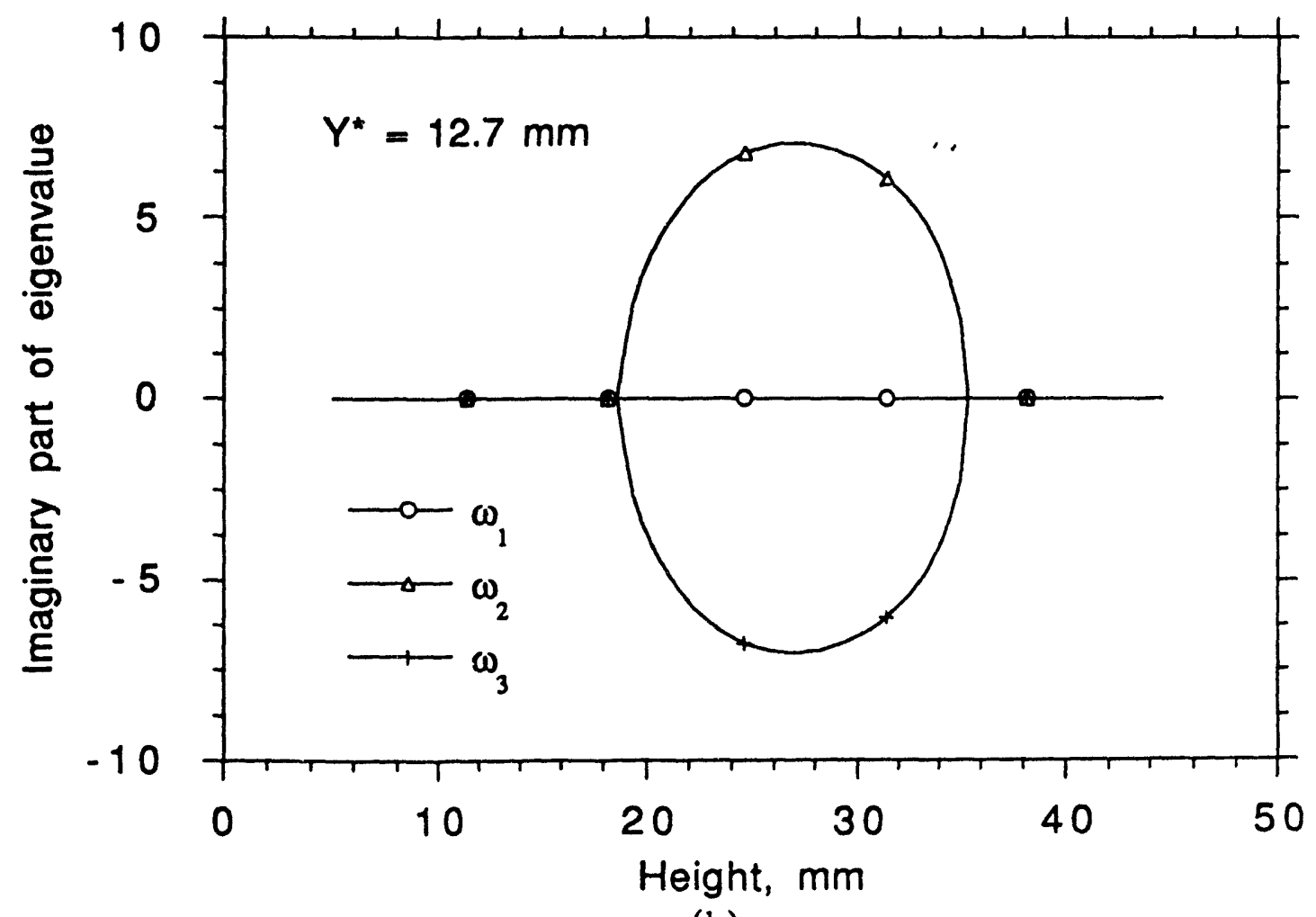

(b) 


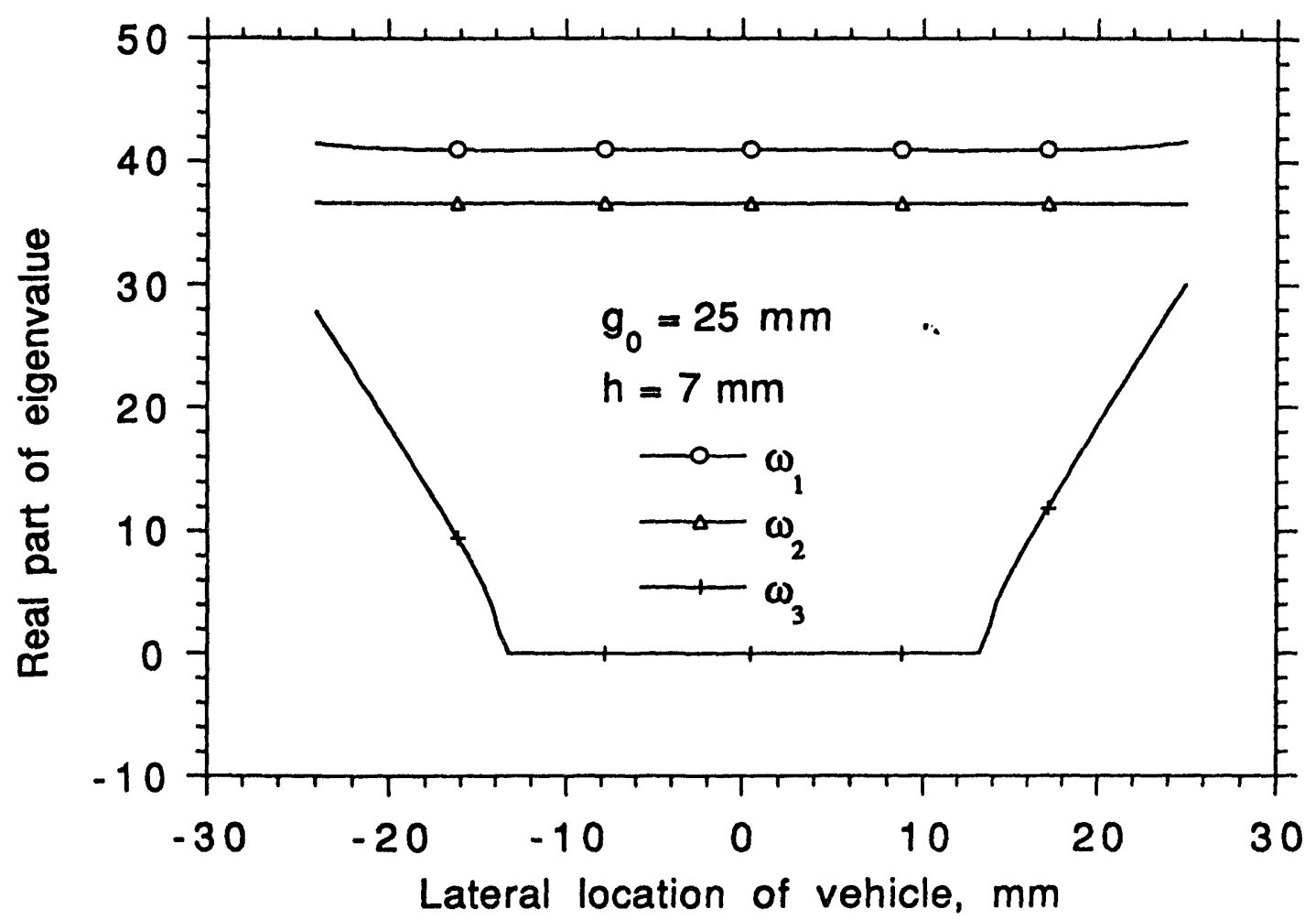

(a)

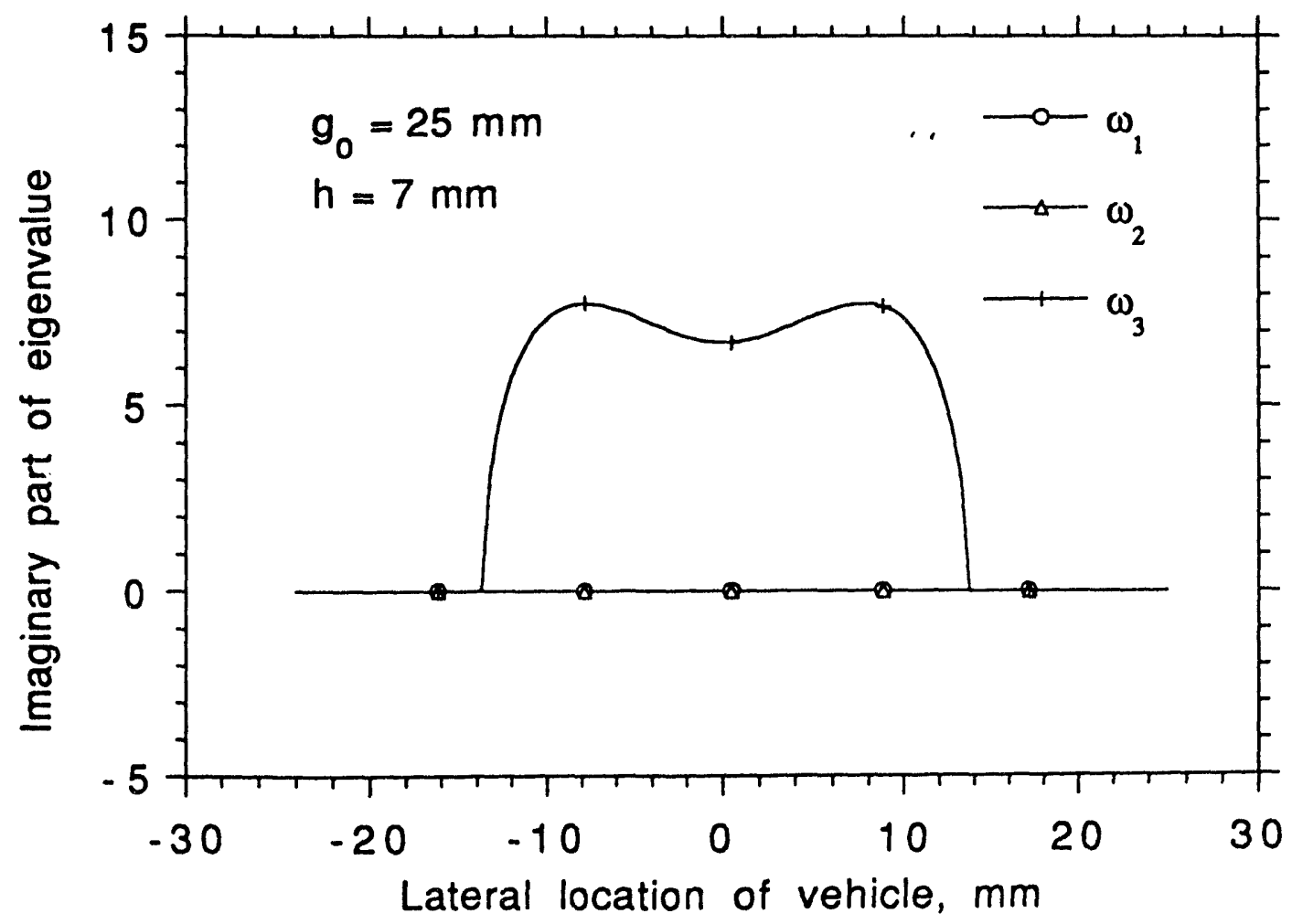

(b) 


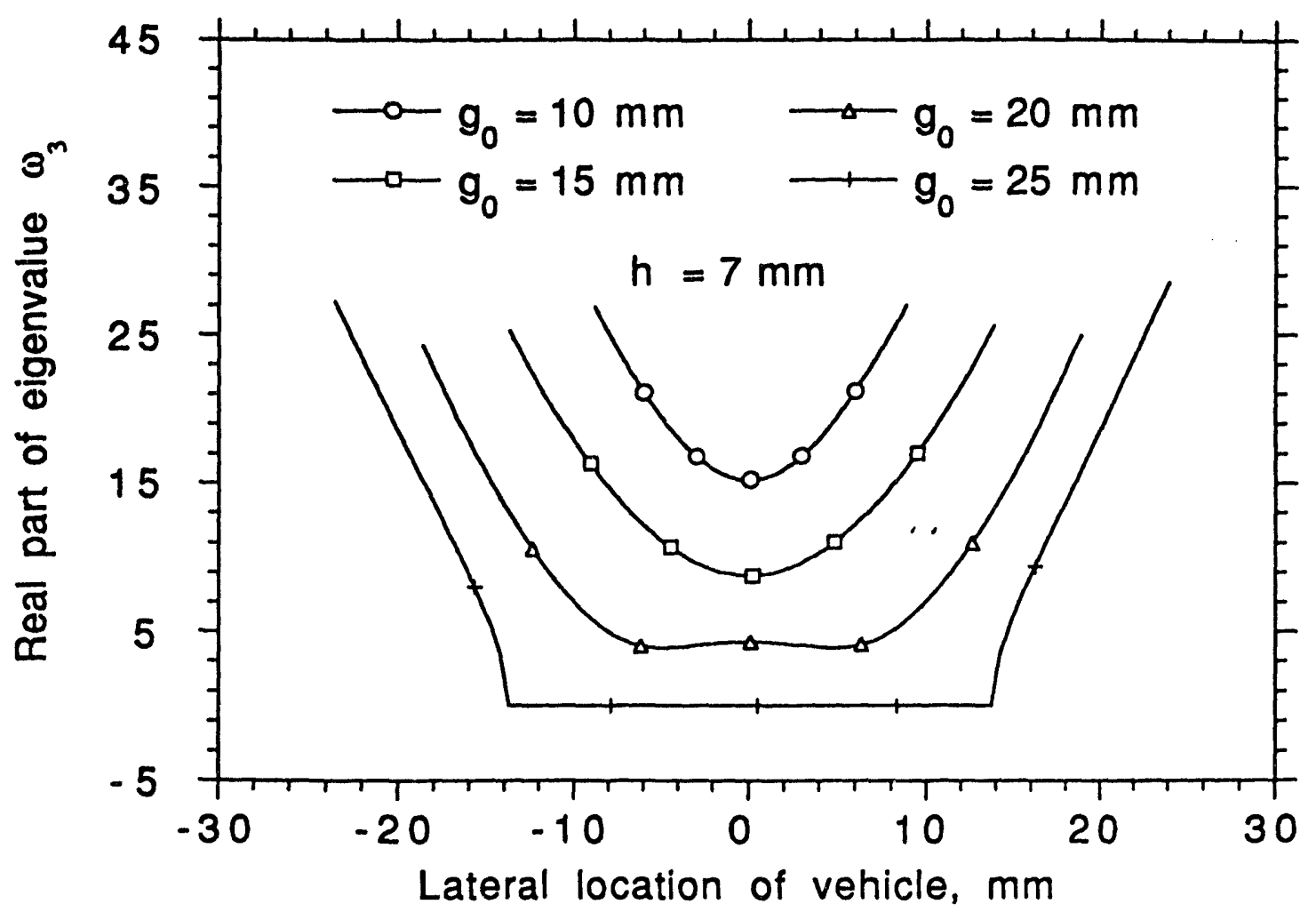

Fig. 9 
11
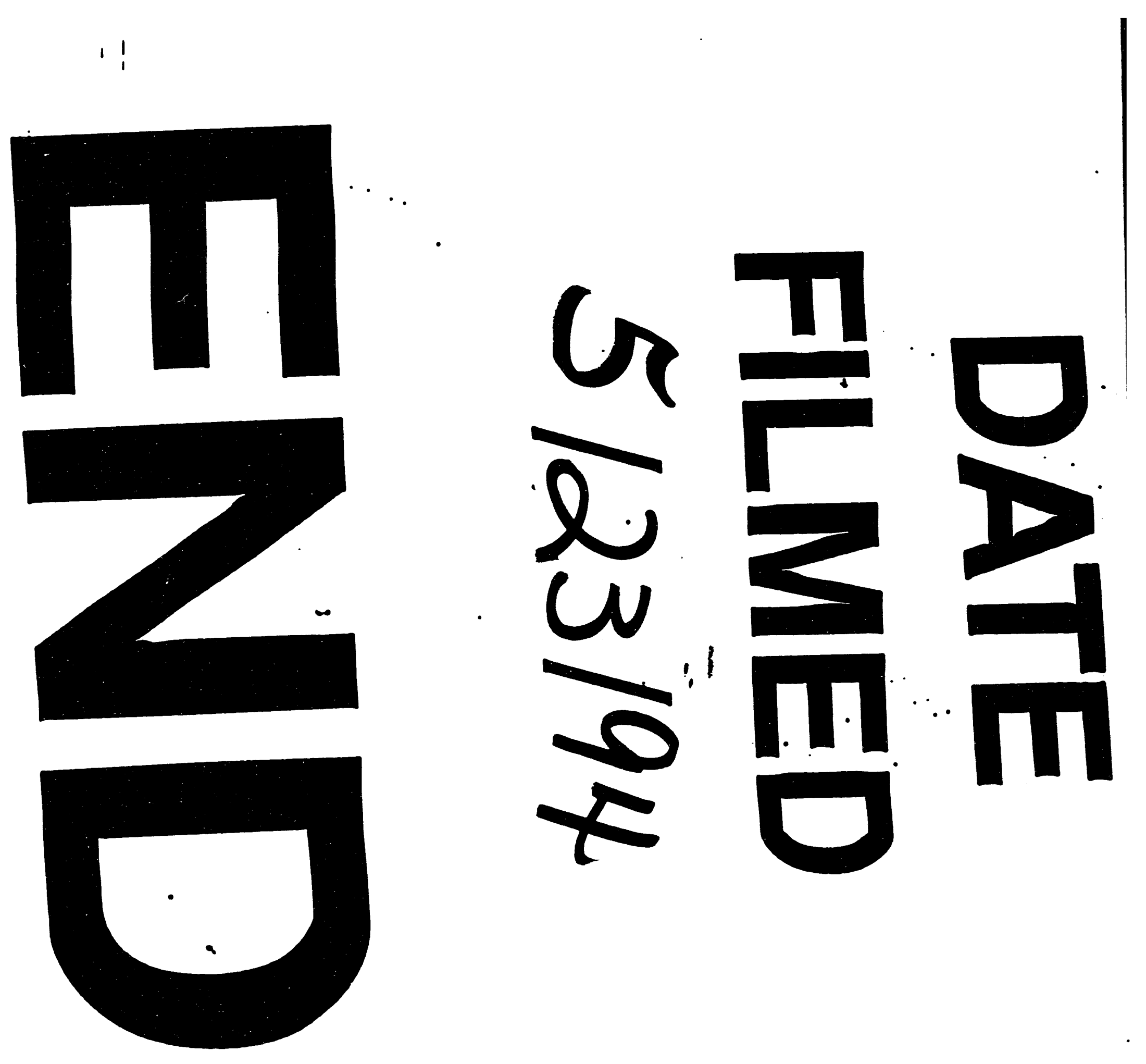
$\longrightarrow$ 